\title{
Polymer Membrane as a Reaction Field II. Effect of Membrane Environment on Permselectivity for Water-Ethanol Binary Mixtures
}

\author{
Masakazu YoshiKawA, Hideto YoKoI, Kohei SANUI, \\ Naoya OGATA, and Takeo SHIMIDZU* \\ Department of Chemistry, Faculty of Science and Technology, \\ Sophia University, 7-1 Kioi-cho, Chiyoda-ku, Tokyo 102, Japan \\ *Division of Molecular Engineering, Graduate School of Engineering, \\ Kyoto University, Kyoto 606, Japan
}

(Received March 9, 1984)

\begin{abstract}
KEY WORDS Synthetic Polymer Membrane / Pervaporation / Permselectivity / Membrane Environment / Dimroth's Solvent Polarity Value $\left(E_{\mathrm{T}}\left(25^{\circ} \mathrm{C}\right)\right) /$
\end{abstract}

Evaluation of membrane polarity ${ }^{1}$ in terms of Dimroth's solvent polarity value $\left(E_{\mathrm{T}}\right.$ $\left(25^{\circ} \mathrm{C}\right)$ ) is carried out using a spiropyran derivative having a long alkyl group, 1octadecyl-3,3-dimethyl- 6'-nitrospiro(indoline$2,2^{\prime}-2 H$-benzopyran), which is a photoresponsible carrier for active-transport of salt through a liquid membrane. ${ }^{2}$ The practical application of this membrane polarity value led to previous reports that the selectivities in the $\mathrm{K}^{+}-\mathrm{Li}^{+}$binary system through common polymer membranes by piezodialysis were closely related to the membrane polarity, $E_{\mathrm{T}}$ $\left(25^{\circ} \mathrm{C}\right)$ values, ${ }^{3}$ and the separation factor for water-various alcohol mixtures through poly(maleimide-co-acrylonitrile) membranes tended to increase as the $E_{\mathrm{T}}\left(25^{\circ} \mathrm{C}\right)$ value of the alcohol separated from that of the membrane despite of dispersion. ${ }^{4}$

In this paper, we survey the effects of the concentration of functional groups which might preferentially interact with water and membrane polarity on permselectivity for the pervaporation of water-alcohol mixtures. The maleimide unit was chosen as the functional group and is effective for the separation of water from water-alcohol mixtures as previously reported. ${ }^{4,5}$ Acrylonitrile and styrene were used as comonomers to form membrane matrices. The potential factors to reign permselectivity for pervaporation of water-ethanol mixtures are discussed.

\section{EXPERIMENTAL}

Maleimide (1) was purified by recrystallization from ethyl acetate. ${ }^{6}$ Styrene (2), acrylonitrile (3), 2,2'-azobisisobutyronitrile (AIBN), cyclohexanone ( $\mathrm{CHN})$, pyridine (Py), and $N, N$-dimethylformamide (DMF) were purified in the usual manner. Chlorobenzene was used without further purification.

Compounds 1 and $\mathbf{2}$ in various molar ratios were placed in an ampule with $0.18 \mathrm{~mol} \%$ of AIBN and solvent. The ampule was sealed after degassing. Copolymerization was carried out at $52^{\circ} \mathrm{C}$ with shaking. The mixture was

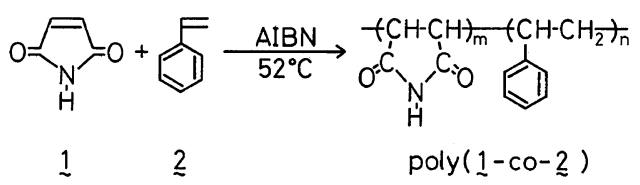


M. Yoshikawa et al.

Table I. Copolymerization of 1 and comonomers ${ }^{\mathrm{a}}$

\begin{tabular}{|c|c|c|c|c|c|c|c|c|c|c|}
\hline \multirow{2}{*}{ Polymer } & \multicolumn{2}{|c|}{ Monomer } & \multirow{2}{*}{$\frac{\text { AIBN }}{\mathrm{mg}}$} & \multirow{2}{*}{$\frac{\text { Solvent }}{\mathrm{cm}^{3}}$} & \multirow{2}{*}{$\frac{\text { Time }}{\mathrm{h}}$} & \multirow{2}{*}{$\frac{\text { Yield }}{\mathrm{g}}$} & \multirow{2}{*}{$\frac{\text { Yield }}{\%}$} & \multicolumn{2}{|c|}{ Mol fraction of $\mathbf{1}$ in } & \multirow{2}{*}{$\frac{\eta_{\mathrm{sp}} / c^{\mathrm{b}}}{\mathrm{dm}^{3} \mathrm{~g}^{-1}}$} \\
\hline & $1 / \mathrm{g}$ & Comonomer $/ \mathrm{g}$ & & & & & & Monomer & Polymer & \\
\hline 4 & 0.097 & 52.04 & 122.6 & $\mathrm{CHN} / 20$ & 7.0 & 3.74 & 7.17 & 0.002 & 0.042 & 0.0768 \\
\hline 5 & 0.097 & 52.02 & 122.6 & Py $/ 50$ & 5.5 & 3.32 & 6.37 & 0.002 & 0.075 & 0.0650 \\
\hline 6 & 0.813 & 4.00 & 13.3 & $\mathrm{DMF} / 10$ & 89.5 & 3.55 & 73.76 & 0.100 & 0.065 & 0.1111 \\
\hline
\end{tabular}

${ }^{\text {a }}$ Polymerization temp, $52^{\circ} \mathrm{C}$.

b Reduced viscosity was measured at $c=1.00 \mathrm{~g} \mathrm{dm}^{-3}$ at $30^{\circ} \mathrm{C}$. Py was used as a solvent for 4 and $\mathbf{5}$, and DMF for $\mathbf{6}$.

c $\mathbf{2}$ was employed as a comonomer for $\mathbf{4}$ and $\mathbf{5}$, and $\mathbf{3}$ for $\mathbf{6}$.

poured into methanol and filtered. Poly(1-co3), 6, was synthesized as previously described. ${ }^{4}$ The results of the copolymerization are shown in Table I. The chemical composition of the copolymer was determined by elemental analysis of carbon and nitrogen.

The poly(1-co-2) membrane was obtained by casting a polymer solution $\left(300 \mathrm{~g} \mathrm{dm}^{-3}\right)$. $\mathrm{CHN}$ and Py were employed as solvents for preparation of $\mathbf{4}$ and 5 membranes, respectively. The solution was poured onto a glass plate with a glass rod and $0.15 \mathrm{~mm}$ spacer, allowing the solvent to evaporate at $40^{\circ} \mathrm{C}$. The thickness of the membrane was $20-26 \mu \mathrm{m}$. The $\mathbf{6}$ membrane was prepared as previously described (membrane thickness, $20-25 \mu \mathrm{m}$ ). ${ }^{4}$

Permeation of water-ethanol mixtures was carried out through the membranes by an ordinary pervaporation technique. The membrane area was $12.6 \mathrm{~cm}^{2}$, of the up-stream compartment was $200 \mathrm{~cm}^{3}$, and the downstream pressure was kept about $400 \mathrm{~Pa}(3.0$ torr). Pervaporation experiments were carried out at a constant temperature of $15^{\circ} \mathrm{C}$. The separation analysis was carried out with a Hitachi 023 Gas Chromatograph equipped with a 1-m-long column packed with Porapak Q.

The separation factor, $\alpha$, is defined as

$$
\alpha=\frac{Y_{\text {Water }} / Y_{\text {Ethanol }}}{X_{\text {Water }} / X_{\text {Ethanol }}}
$$

where $Y_{i}$ 's are weight fractions of permeates and $X_{i}^{\prime}$ 's are those of feeds, respectively.
Dimroth's solvent polarity values, $E_{\mathrm{T}}$ $\left(25^{\circ} \mathrm{C}\right)$, of these three membranes were measured as described previously, ${ }^{1}$ using 1-octadecyl-3,3-dimethyl-6'-nitrospiro(indoline$2,2^{\prime}-2 H$-benzopyran) as the indicator. A 250 W high-pressure mercury lamp was used as the light source. Absorption spectra were measured with a Shimadzu UV-240 UVVisible Recording Spectrophotometer.

\section{RESULTS AND DISCUSSION}

Figure 1 indicates the results of the pervaporation experiment, where weight fractions of water in the permeates are plotted against those in the feeds. These experiments were carried out at $15^{\circ} \mathrm{C}$ through the 4 membrane. Figure 1 shows that water is preferentially permeated through this membrane.

Figure 2 indicates the effects of feed composition on the flux and separation factor, $\alpha$, at $15^{\circ} \mathrm{C}$. As showsn in Figure 2, the $\alpha$ values were maintained between 10 and 15 except the point where the weight fraction of water in the feed was 0.068 despite the change in the feed composition. The flux number was also held at a constant value, about $2.3 \mathrm{~g} \mathrm{~m}^{-2} \mathrm{~h}^{-1}$, but a steep rise in flux was observed at the very point where the weight fraction of water in the feed was 0.068 . On the other hand, the $\alpha$ value dropped down to 2.8 from 11.8 at this point in response to an increase in the flux number. From the profiles of $\alpha$ and the flux shown in Figure 2, it was deduced that the $\mathbf{4}$ membrane 
Table II. Pervaporation ${ }^{\mathrm{a}}$ of water-ethanol binary mixture through various membranes

\begin{tabular}{|c|c|c|c|c|c|c|c|c|}
\hline \multirow{2}{*}{$\begin{array}{l}\text { Run } \\
\text { No. }\end{array}$} & \multirow{2}{*}{ Membrane } & \multirow{2}{*}{ Comonomer } & \multirow{2}{*}{$\begin{array}{c}\text { Mol fraction } \\
\text { of } 1 \text { unit }\end{array}$} & \multicolumn{2}{|c|}{ Weight fraction of water in } & \multirow{2}{*}{$\begin{array}{l}\text { Separation } \\
\text { factor }(\alpha)\end{array}$} & \multirow{2}{*}{$\frac{\text { Flux }}{\mathrm{g} \mathrm{m}^{-2} \mathrm{~h}^{-1}}$} & \multirow{2}{*}{$\frac{E_{\mathrm{T}}\left(25^{\circ} \mathrm{C}\right)}{\mathrm{kcal} \mathrm{mol}^{-1}}$} \\
\hline & & & & Feed & Permeate & & & \\
\hline 1 & 4 & 2 & 0.042 & 0.536 & 0.945 & 14.93 & 3.174 & $29.9^{\mathrm{b}}$ \\
\hline 2 & 5 & 2 & 0.075 & 0.498 & 0.958 & 22.71 & 3.708 & $31.3^{\mathrm{c}}$ \\
\hline 3 & 6 & 3 & 0.065 & 0.510 & 0.997 & 319.3 & 10.08 & $53.3^{\mathrm{d}}$ \\
\hline
\end{tabular}

${ }^{\text {a }}$ Operating temp, $15^{\circ} \mathrm{C}$; down-stream pressure, $400 \mathrm{~Pa}$ (3.0 torr).

b $\lambda_{\max }^{\text {Vis }}$ was $608 \mathrm{~nm}$.

c $\lambda_{\max }^{\operatorname{Vis}}$ was $604 \mathrm{~nm}$.

d Cited from ref 4.

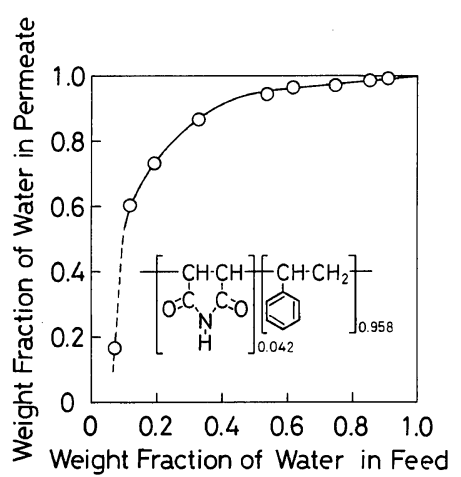

Figure 1. Effects of feed composition on the separation of water-ethanol mixtures at $15^{\circ} \mathrm{C}$ : Down-stream pressure, $400 \mathrm{~Pa}$ (3.0 torr); 1 fraction, 0.042 .

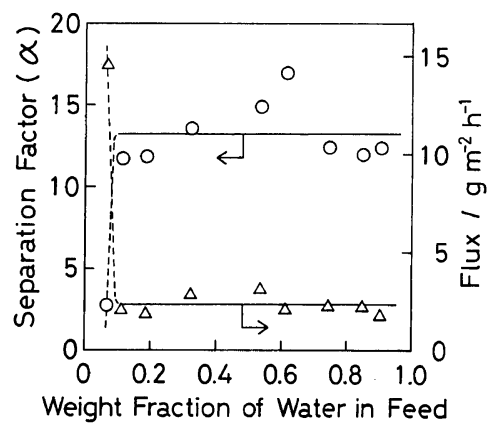

Figure 2. Effects of feed composition on flux and the separation factor, $\alpha$, in water-ethanol pervaporation through poly(1-co-2), 4, membrane at $15^{\circ} \mathrm{C}$ : 1, fraction, 0.042 .

swelled abruptly at this point. However, swelling of the membrane could hardly be observed during any of the pervaporation experiments and even at this point.

Table II shows the effect of the functional group (maleimide unit) concentration and that of environment (membrane polarity) around the functional group on pervaporation. In these pervaporation experiments, the weight fraction of water in the feed was fixed at about 0.5. Comparing run no. 1 with 2 in Table II, the $\mathbf{5}$ membrane, containing maleimide unit about 1.8 times as much as the $\mathbf{4}$ membrane, permeated water more preferentially than the 4 membrane. This was interpreted as follows. More water was incorporated into the 5 membrane than the $\mathbf{4}$ membrane by a hydrogenbonding interaction between water and the maleimide unit in the membrane. As a result, the 5 membrane gave a higher separation factor ( $\alpha$ value) than the 4 membrane. Nevertheless, water was preferentially permeated more than ethanol through both the 4 and 5 membranes as was previously reported poly(maleimide-co-acrylonitrile) membranes. ${ }^{4,5}$

Consideration of environmental effects was required as the next step. Table II indicates that the $\mathbf{6}$ membrane preferentially permeated water with a high selectivity in comparison to the selectivity through the $\mathbf{5}$ membrane, whose unit mol fraction of $\mathbf{1}$ was nearly the same value as that for the $\mathbf{6}$ membrane. The microscopic polarity parameter of these three membranes are also summarized in Table II. It was concluded that the polarity of the $\mathbf{4}$ and 5 membranes was equivalent to that of hexane 
and the polarity of the 6 membrane to that of $\mathrm{N}$-methylformamide or 2-methoxyethanol when compared with the values for small molecules. ${ }^{7,8}$ Although only two different environments of membranes were available, the $\alpha$ value tended to decrease as the $E_{\mathrm{T}}\left(25^{\circ} \mathrm{C}\right)$ value of water, $63.1 \mathrm{~K} \mathrm{cal} \mathrm{mol}^{-1}$, deviated from that of the membrane. It is assumed that the membrane having an $E_{\mathrm{T}}\left(25^{\circ} \mathrm{C}\right)$ value close to that of water easily incorporated water into the membrane causing an increase in the $\alpha$ value.

This paper shows that not only the amount of functional group (maleimide unit), possibly interacting preferentially with water by a hydrogen-bonding interaction, in the membranes but also the environment (membrane polarity) about the functional group regulated the permselectivity of water-ethanol binary mixtures.

\section{REFERENCES}

1. T. Shimidzu and M. Yoshikawa, Polym. J., 15, 135 (1983).

2. T. Shimidzu and M. Yoshikawa, J. Membrane Sci., 13, 1 (1983)

3. T. Shimidzu and M. Yoshikawa, Nippon Kagaku Kaishi, 958 (1983).

4. M. Yoshikawa, H. Yokoi, K. Sanui, and N. Ogata, J. Polym. Sci., Polym. Chem. Ed., in press.

5. M. Yoshikawa, H. Yokoi, K. Sanui, and N. Ogata, $J$. Polym. Sci., Polym. Lett. Ed., 22, 125 (1984).

6. Y. Matsubara, J. Asakura, N. Yamashita, H. Sumitomo, and T. Maeshima, Kogyo Kagaku Zasshi, 72, 2658 (1969)

7. K. Dimroth, C. Reichardt, T. Siepmann, and F. Bohlmann, Ann. Chem., 661, 1 (1963).

8. C. Reichardt, Angew. Chem. Internat. Ed., 4, 29 (1965). 